Copyright (C) 2020 by Cherkas Global University

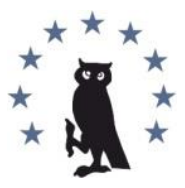

Published in the USA

Zhurnal ministerstva narodnogo prosveshcheniya

Has been issued since 2014 .

E-ISSN: $2413-7294$

2020. $7(2): 32-39$

DOI: $10.13187 /$ zhmnp.2020.2.32

https://zmnp.cherkasgu.press

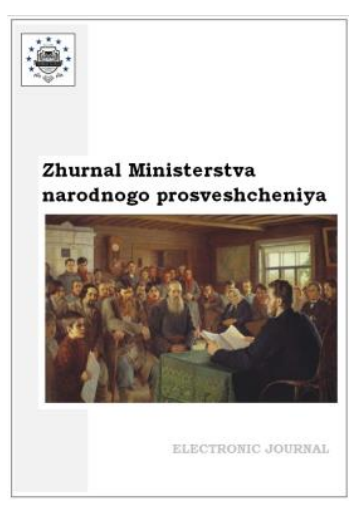

\title{
Articles
}

\section{Managing the Functional State of the Inventor}

Alexander I. Karmanchikov a, *

a Udmurt State University, Izhevsk, Russian Federation

\begin{abstract}
The object of research in the article is the system for the creation and protection of intellectual industrial property. Attention is paid to the possibility of accelerating the process of finding optimal effective solutions, the possibilities of enhancing the creative activity of the individual and creative groups are revealed, the possibilities of increasing the effectiveness of creative activity are highlighted by taking into account the psychological characteristics of the individual, the specifics of the relationship of different types of personality in the creative group.

A systematic analysis of the creation of industrial intellectual property objects reveals a low level of psychological culture of employees of enterprises. Specialists and creative teams capable of quickly identifying technical problems and finding effective solutions are becoming an increasingly popular category in the labor market. An increasingly urgent task is to create creative groups that effectively use the methods of technical creativity to accelerate the process of finding effective technical solutions to production problems. The objective results of the system analysis of the methodology of invention make it possible to more effectively use the intellectual resources of the university, region and country.

Motivation for creative activity, activation of the search for effective solutions depend on the emotional state of the inventor or the creative group, emotions become faithful guides and reflection of social information into the world of consciousness, where this information is comprehended and processed.

An integrated approach to the system for finding effective solutions to production problems includes, as one of the most important, a system for increasing the efficiency of "human resources".

Keywords: system analysis, methodology of invention, activation of technical creativity, psychological characteristics of a person.
\end{abstract}

\section{1. Введение}

Процессы усовершенствования техники зависят от множества условий, аспектов, факторов и управляющих воздействий. Потребность в исследованиях процессов создания объектов интеллектуальной собственности становится всё более актуальной, растет потребность предприятий в инновациях, передовых технологиях. Предприятия не могут себе позволить стабильное производство продукции, без снижения себестоимости,

\footnotetext{
* Corresponding author

E-mail addresses: karmai@bk.ru (A.I. Karmanchikov)
} 
металлоемкости, энергоемкости; без повышения качества, надежности, тактикотехнических характеристик выпускаемых объектов. Сохранить высокий уровень конкурентоспособности и доходности многим предприятиям позволяет внимание к интеллектуальным ресурсам, к созданию инноваций, изобретений. Количество и качество результатов интеллектуальной деятельности зависит, прежде всего, от интеллектуальных ресурсов предприятия. Заставить сотрудника создавать патентоспособные технические решения не возможно, однако определенные условия работы, способы мотивации к творческой деятельности могут позитивно влиять на создание эффективных результатов интеллектуальной деятельности. В данной работе рассматриваются отдельные аспекты управления процессом создания интеллектуальной продукции связанные с личностью изобретателя, его эмоциональным состоянием; с выявлением факторов, влияющих на активизацию творческой деятельности.

\section{2. Результаты и обсуждение \\ Функциональное состояние изобретателя}

Функциональное состояние можно рассматривать как устойчивое состояние конкретной личности, что позволяет эффективно выполнять определённый вид деятельности. Относительно творческой деятельности изобретателя, эффективным функциональное состояние личности можно считать, если процесс творческой деятельности позволяет стабильно получать новые, полезные технические решения проблем на высоком изобретательском уровне.

Можно выделить целый комплекс наук о трудовой деятельности: инженерная психология, психология труда, эргономика, психология личности, методология творчества. Мотивация к творчеству, активизация творческой деятельности, факторы, влияющие на эффективность деятельности творческой личности, взаимодействие и взаимовлияние личностей в процессе творчества, самоактивизация и самоуправление своим состоянием, эти и многие другие аспекты позволяют систематизировать процесс творческой деятельности, эффективно влиять на этот сложный вид интеллектуальной деятельности. Появляется возможность выявить отдельные элементы сложной системы творчества, позволяющие позитивно управлять процессом создания новых и эффективных результатов интеллектуальной деятельности.

Исследования и анализ психологических и социально-психологических аспектов функционального состояния работающего человека в условиях реальной деятельности в первой половине XX века в России проводились А.А. Ухтомским, а за рубежом Г. Селье.

Основным положением А.А. Ухтомского является выявление естественнонаучных основ нравственного поведения людей, отражение физиологических механизмов, которые создают разнообразие психологических типов личности. Доминирующая мотивация личности является интегратором и регулятором действия разного уровня. Выявление, или формирование и развитие, такой доминанты может быть одним из элементов влияния на процесс творчества, и регулирования творческой деятельностью.

Закономерности развития нашего сознания и мышления остаются объектом пристального исследования многих ученых. Социобиологи называют эти закономерности эпигенетическими правилами. «Эволюция мышления предполагает глубокие изменения в генах, мозге, эпигенетических правилах, что накладывает отпечаток на историю развития культуры в целом» (Быданова, Быданов; Соколова, 2005; Павлова, 2017; Ухтомский, 2020).

Исследования Ганса Селье показывают, что стресс негативный фактор в нашей жизни, который может привести ко многим заболеваниям, однако в нём залажен и большой позитивный потенциал: «...не только беда, но и великое благо, ведь без стрессов различной природы наша жизнь была бы скучна и однообразна». Стресс «...важнейший процесс адаптации, тренировки организма» (Селье). По нашему мнению, стресс ещё один элемент управления и регулирования в системе поиска эффективных решений. Многие изобретения были созданы в стрессовой ситуации, в период войны. С.П. Королев и другие ученые работали и находили эффективные и перспективные решения, находясь в заключении в период сталинских репрессий. Г. Селье, как врач, анализировал, прежде всего, медицинские аспекты воздействия стресса на человека. Исследование позитивных 
возможностей и границ использования стресса в техническом творчестве требует всестороннего и глубокого исследования.

Исследователи используют следующие основные подходы для анализа функциональных состояний: энергетический, феноменологический, поведенческий, комплексный и системный (Psychological aspects..., 1976; Леонова, 2007; Бодров, 2009; Леонова, Кузнецова). Важно подчеркнуть, что функциональное состояние рассматривается как результат включения человека в процесс активной и целенаправленной деятельности. Ведущую роль в этом играют мотивационные установки работника и доступные ему в конкретный период времени внутренние ресурсы для выполнения решаемых задач. Отсутствие понимания этого сводит к нулю все управленческие усилия руководителя.

Следует отметить различные подходы к классификации функциональных состояний, среди которых следует обратить внимание, в рамках нашего исследования, на вариант классификации по типу механизмов регуляции деятельности.

Первая группа: по степени адекватности функциональных состояний, как ответной системной реакции требованиям выполнения задач в определенных ситуативных условиях. Ответная системная реакция может в виде адекватной мобилизации и динамического рассогласования. Конечно, для эффективной творческой деятельности важно добиваться объективно обоснованной адекватной мобилизации. Если реакция рассогласования, следует приложить усилия для выработки объективного понимания имеющихся возможностей, ресурсов и сложившихся условий, чтобы произошла адекватная мобилизация.

Вторая группа: классификация по степени накопления неблагоприятной симптоматики: экстенсивные и интенсивные функциональные состояния. Для управления процессом создания интеллектуальной собственности важную роль играет понимание свойств функциональных состояний.

Важную, определяющую роль играет система и технология диагностики функциональных состояний. Диагностика позволяет прогнозировать не только перспективы ближайшего и отдаленного развития ситуации, но и определить возможную объективную реакцию конкретной личности на изменения условий, на определенные управляющие воздействия.

\section{Результаты исследования эффективности работы творческой группы}

Наши исследования показывают, что в случае использования широко известного метода технического творчества - метода мозгового штурма, важную роль играют определённые организационные и управленческие действия организаторов, руководителей процесса поиска эффективных решений предлагаемой проблемы (Карманчиков, 2005; Карманчиков, 2012а).

Один из этапов мозгового штурма - формирование двух групп: генераторов и экспертов. Без диагностики индивидуальных психологических особенностей личности, стиля мышления, функционального состояния трудно объективно прогнозировать эффективную работу в составе генераторов идей или в группе экспертной оценки предлагаемых решений.

Наш многолетний опыт проведения мозгового штурма показывает, что формирование групп (генераторов, экспертов) с учетом индивидуальной психологической характеристики личности, преобладающего стиля мышления, анализа функционального состояния кандидатов для участия в той или иной творческой группе, по многим показателям выше, чем произвольное формирование рабочих групп. Среди показателей, которые фиксировались и анализировались, получали сравнительную характеристику, были следующие: количество предлагаемых решений проблемы, идей каждым членом группы; количество предложений по развитию, улучшению предложенного варианта решения другим членом группы; возвращение к ранее предлагавшимся вариантам; визуальная оценка работы группы.

Общее количество студентов 3-4 курсов участвовавших в эксперименте в период с 2012 по 2019 годы составляет: в сформированных с учетом рекомендаций психолога группах 478 человека; без учета рекомендаций психолога - 459 человек. Из числа студентов, прошедших тестирование, формировалась экспериментальная группа в количестве 
8-10 человек. Контрольная группа формировалась по общепризнанным рекомендациям для проведения мозгового штурма. К основным рекомендациям формирования группы генераторов обычно относятся следующие: «не приглашать прирожденных скептиков и критиков, стараются привлечь людей с фантазией, специалистов - смежников (конструктора, технолога, экономиста, снабженца и одного - двух человек «со стороны», не имеющего никакого отношения к задаче (врача, парикмахера, почтового работника)» (Карманчиков, 2012b).

В основе психологического тестирования лежит типология личности, предложенная К.Г. Юнгом (Юнг, 2017). Психологическое тестирование студентов проводилось предварительно по методике профессора Л.Н. Собчик (Собчик, 2002), В.В. Гуленко (Гуленко, 1995). В процессе тестирования определялся преобладающий стиль мышления, индивидуальные психологические характеристики. В предложенной К.Г. Юнгом типологии личности выделены 4 дихотомических шкалы: экстраверсия - интроверсия (Е-I, восприятие информации); сенсорика - интуиция (S-N, переработка информации); логика - этика (F-T, тип мышления); рациональность - иррациональность (Р-Ј, стиль жизни). После тестирования определяется у конкретной личности один из возможных 16 психологических типов. Общепринятым является буквенное обозначение каждого психологического типа, один из показателей по каждой шкале. Например, ENTP - интуитивно-логический иррациональный экстраверт.

В группу генераторов идей при проведении мозгового штурма включались студенты с преобладающим интуитивным стилем мышления, в индивидуальной психологической характеристике студентов присутствовала интуиция (N), это 8 психотипов: INTP, ENTP, INFP, ENFP, INTJ, ENTJ, INFJ, ENFJ. Другие 8 психологических типов, у которых преобладает такой показатель как сенсорика, обладают хорошими данными для работы в группе экспертов. Конечно, нельзя полностью игнорировать традиционные рекомендации по формированию групп генераторов и экспертов при проведении различных вариантов такого метода технического творчества, как мозговой штурм. Однако, преобладающий стиль мышления играет определяющую роль в профессиональной деятельности. Если провести аналогию с игрой в баскетбол, для формирования команды определяющим является рост игрока, однако и другие характеристики имеют значение, хотя и в меньшей степени.

Представители академической психологии принимают типологию К.Г.Юнга, соционику (направление конца XX века в СССР) с многочисленными оговорками, потому что не все исходные элементы теории подтверждены после накопления эмпирических данных (Крегер, Тьюсен; Букалов; Абельская, 2006; Sipps et al., 1985; McCrae, Costa, 1989; Pittenger, 1993; In the Mind's Eye, 1991; Шмелев, 2010). Однако в аспекте определения стиля мышления типология показывает высокий уровень достоверности, поэтому в нашем исследовании это оправдано.

Проведенное нами исследование по определению преобладающего стиля мышления индивидуальных психологических характеристик студентов ИГМА в 2003 году и студентов ИжГТУ в 2004 и 2018 годах показало, что среди студентов (76\%) ИГМА преобладает эмоциональный стиль мышления (44 человека из 58 прошедших тестирование). У 86 \% студентов ИжГТУ преобладающим оказался логический стиль мышления, 64 человека из 74 прошедших тестирование.

Основные требования будущей профессии к стилю мышления специалистов у студентов ИГМА (эмоциональный стиль) и у студентов ИжГТУ (логический стиль) соответствуют преобладающему стилю мышления, т.е. сделанный поступавшими в вуз выбор направления обучения, часто интуитивно, был правильный.

\section{Обработка результатов исследования}

Проведенный нами анализ результатов проведенных многократно (57 групп) экспериментов по эффективности формирования творческих групп генераторов и экспертов для проведения традиционного мозгового штурма показал, что эффективность деятельности этих групп будет существенно выше, если в процессе их формирования учитывается индивидуально-психологическая характеристика личности, преобладающий стиль мышления. Количество предлагаемых решений проблемы, идей каждым членом экспериментальной группы выросло в сравнении с контрольной группой в несколько раз. Если в контрольной группе каждый член группы предлагал 2-3 варианта решения 
проблемы, то в группах, которые были сформированы с учетом тестирования, преобладающего стиля мышления, таких предложений было 8-12. Количество предлагаемых решений возрастало в 4-5 раз.

В таком показателе как количество предложений по развитию, улучшению варианта решения, предложенного другим членом группы, наблюдалось увеличение в 1,5-2 раза предложений по улучшению, совершенствованию вариантов, которые были высказаны другими членами группы генераторов, а в контрольной группе изменений не наблюдалось. В контрольных группах чаще наблюдалось возвращение к ранее предлагавшимся вариантам, идеям, вариантам решения поставленной проблеме.

Визуальная оценка работы каждой группы показывает, что взаимопонимание, поддержка, взаимодействие, общая оценка эффективности работы выше в группах, которые формировались с учетом результатов тестирования, чем в группах, которые формировались по общепризнанным рекомендациям, т.е. без предварительного тестирования (контрольные группы).

\section{3. Заключение}

Важными элементами управления и регулирования процессов создания эффективных технических решений является объективное восприятие и понимание организационных и управленческих воздействий, позитивное отношение к мотивации к творчеству; законодательным актам в области стимулирования и материального вознаграждения изобретателей; патентной политикой государства, предприятия, вуза. В конце XX века внимание многих исследователей направлено на изучение роли «человеческого фактора» в повышении эффективности и безопасности в производстве. Нами были рассмотрены лишь отдельные психологические аспекты личности в процессе творческой деятельности, определены пути повышения эффективности этой деятельности. Однако роль «человеческого фактора» в технике очень важна и её влияние на все процессы становятся всё весомее. Игнорирование психологических особенностей личности негативно влияет на производственные процессы и снижает жизненные ресурсы самой личности. Необходим системный анализ позитивного и негативного влияния психологических особенностей личности, эмоциональное состояние человека в процессе производственной, творческой деятельности. Поэтому исследования в этой области будут продолжаться и углубляться.

Для эффективного, оптимального управления функциональным состоянием изобретателя или любого другого специалиста важно понимать и выделять его сильные и слабые стороны, чтобы поручать выполнение той части, вида деятельности, которая соответствует сильным сторонам этой личности. Использование рекомендаций психологов в формировании творческих групп позволяет повысить эффективность использования методов технического творчества в процессе поиска эффективных технических решений актуальных производственных проблем.

\section{Литература}

Абельская, 2006 - Абельская Е.Ф. Типоведческое исследование психического склада личности. Автореф. ... канд. психол. наук: 19.00.01. Екатеринбург, 2006. 25 с.

Бодров, 2009 - Бодров B.A. Профессиональное утомление: Фундаментальные и прикладные проблемы. М.: Институт психологии РАН, 2009.

Букалов - Букалов А.В. Соционика, типология Юнга и Майерс-Бриггс: сходства и различия. [Электронный ресурс]. URL: http://socionic.info/pdf/as498.pdf (дата обращения: 30.10.2020).

Быданова, Быданов - Бъданова Н.Б., Быданов В.Е. Учение о доминанте А.А. Ухтомского в контексте эволюционной эпистемеологии. [Электронный ресурc]. URL: https://www.razumei.ru /blog/vodjanitsa/4753/nasledie-russkogo-psihofiziologa-a-a-uhtomskogo (дата обращения: 21.10.2020).

Гуленко, 1995 - Гуленко В.В. Менеджмент слаженной команды. Новосибирск: РИПЕЛ, 1995. 192 c.

Карманчиков, 2005 - Карманчиков А.И. Педагогическое прогнозирование творческой активности личности. Ижевск: Изд-во ИПК и ПРО УР, 2005. 56 с. 
Карманчиков, 2012а - Карманчиков А.И. Прогностическая логистика в системе образования: Монография. Ижевск: Изд-во «Удмуртский университет», 2012. 226 с.

Карманчиков, 2012b - Карманчиков А.И. Методы инженерного творчества. Учебнометодическое пособие. Ижевск: Изд-во «Удмуртский университет», 2012. 174 с.

Крегер, Тьюсен - Крегер О., Тъюсен Д. Типы людей. [Электронный ресурс]. URL: https://docplayer.ru/29180263-O-kreger-dzh-m-tyuson-tipy-lyudey.html (дата обращения: 12.08.2020).

Леонова, 2007 - Леонова А.Б. Структурно-интегративный подход к анализу функциональных состояний человека // Вестник Московского университета. Серия 14: Психология. 2007. № 1. С. 87-103.

Леонова, Кузнецова - Леонова А.Б., Кузнецова А.С. Психологические технологии управления состоянием человека. [Электронный ресурc]. URL: https://www.psychologos.ru/ articles/view/psihologicheskie-tehnologii-upravleniya-sostoyaniem-cheloveka.-leonova-a.b.zptkuznecova-a.s

Павлова, 2017 - Павлова Л.П. Доминанты деятельного мозга. Системный психофизиологический подход к анализу ЭЭГ. СПб.: ИНФОРМ-НАВИГАТОР, 2017. 442 с.

Селье - Селье Г. Концепция стресса. [Электронный ресурс]. URL: https://econet.ru /articles/177393-gans-selie-kontseptsiya-stressa (дата обращения: 18.10.2020).

Собчик, 2002 - Собчик Л.Н. Диагностика индивидуально-типологических свойств и межличностных отношений. СПб: Изд-во «Речь», 2002. 96 с.

Соколова, 2005 - Соколова Л.В. Развитие учения о биосоциальной природе человека в трудах А.А. Ухтомского. Дисс. ... Д-ра биол. наук, спец. 03.00.13. СПб., 2005. 252 с.

Ухтомский, 2020 - Ухтомский А.А. Доминанта. СПб.: Изд-во «Питер», 2020. 310 с.

Шмелев, 2010 - Шмелев А.Г. Уже не соционика, но ещё не дифференциальная психология // Вестник ЮУрГУ. Серия: Психология. 2010. № 27 (203). С. 104-108.

Юнг, 2017 - Юнг К.Г. Очерки по аналитической психологии. Перевод С. Лорие, В.А. Поликарпов. Минск: Изд-во «Харвест», 2017.

In the Mind's Eye, 1991 - In the Mind's Eye: Enhancing Human Performance / Eds. D. Druckman, R.A. Bjork. Washington (DC): National Academy Press, 1991.

McCrae, Costa, 1989 - McCrae R.R., Costa P.T. Reinterpreting the Myers-Briggs Type Indicator from the Perspective of the Five-Factor Model of Personality // Journal of Personality. 1989. Vol. 57. № 1. P. 12-40.

Pittenger, 1993 - Pittenger D.J. Measuring the MBTI... and Coming Up Short // Journal of Career Planning \& Placement. 1993. January.

Psychological aspects..., 1976 - Psychological aspects and physiological correlates of work and fatigue. Ed. by E. Simonson and P. C Weiser. New York, 1976.

Sipps et al., 1985 - Sipps G.J., Alexander R.A., Friedt L. Item Analysis of the Myers-Briggs Type Indicator // Educational and Psychological Measurement. 1985. Vol. 45. № 4. Pp. 789-796.

\section{References}

Abel'skaya, 2006 - Abel'skaya, E.F. (2006). Tipovedcheskoe issledovanie psikhicheskogo sklada lichnosti [Typological study of the mental makeup of the personality]. Avtoref. ... kand. psikhol. nauk: 19.00.01. Ekaterinburg, 25 p. [in Russian]

Bodrov, 2009 - Bodrov, V.A. (2009). Professional'noe utomlenie: Fundamental'nye i prikladnye problemy [Occupational Fatigue: Fundamental and Applied Problems]. Moscow: Institut psikhologii RAN. [in Russian]

Bukalov - Bukalov, A.V. Sotsionika, tipologiya Yunga i Maiers-Briggs: skhodstva i razlichiya [Socionics, Jung's typology and Myers-Briggs: similarities and differences]. [Electronic resource]. URL: http://socionic.info/pdf/as498.pdf (date of access: 30.10.2020). [in Russian]

Bydanova, Bydanov - Bydanova, N.B., Bydanov, V.E. Uchenie o dominante A.A. Ukhtomskogo $\mathrm{v}$ kontekste evolyutsionnoi epistemeologii [The doctrine of the dominant A.A. Ukhtomsky in the context of evolutionary epistemology]. [Electronic resource]. URL: https://www.razumei.ru/blog/ vodjanitsa/4753/nasledie-russkogo-psihofiziologa-a-a-uhtomskogo (date of access: 21.10.2020). [in Russian] 
Gulenko, 1995 - Gulenko, V.V. (1995). Menedzhment slazhennoi komandy [Well-coordinated team management]. Novosibirsk: RIPEL, 192 p. [in Russian]

In the Mind's Eye, 1991 - In the Mind's Eye: Enhancing Human Performance / Eds. D. Druckman, R.A. Bjork. Washington (DC): National Academy Press, 1991.

Karmanchikov, 2005 - Karmanchikov, A.I. (2005). Pedagogicheskoe prognozirovanie tvorcheskoi aktivnosti lichnosti [Pedagogical forecasting of a person's creative activity]. Izhevsk: Izd-vo IPK i PRO UR, 56 p. [in Russian]

Karmanchikov, 2012a - Karmanchikov, A.I. (2012). Prognosticheskaya logistika v sisteme obrazovaniya [Predictive logistics in the education system]: Monograph. Izhevsk: Izd-vo «Udmurtskii universitet», 226 p. [in Russian]

Karmanchikov, 2012b - Karmanchikov, A.I. (2012). Metody inzhenernogo tvorchestva [Engineering creativity methods]. Study guide. Izhevsk: Izd-vo «Udmurtskii universitet», $174 \mathrm{p}$. [in Russian]

Kreger, T'yusen - Kreger, O., T'yusen, D. Tipy lyudei [Types of people]. [Electronic resource]. URL: https://docplayer.ru/29180263-O-kreger-dzh-m-tyuson-tipy-lyudey.html (date of access: 12.08.2020). [in Russian]

Leonova, 2007 - Leonova, A.B. (2007). Strukturno-integrativnyi podkhod $\mathrm{k}$ analizu funktsional'nykh sostoyanii cheloveka [Structural-integrative approach to the analysis of human functional states]. Vestnik Moskovskogo universiteta. Seriya 14: Psikhologiya. 1: 87-103. [in Russian]

Leonova, Kuznetsova - Leonova, A.B., Kuznetsova, A.S. Psikhologicheskie tekhnologii upravleniya sostoyaniem cheloveka [Psychological technologies for managing the human condition]. [Electronic resource]. URL: https://www.psychologos.ru/articles/view/psiholo gicheskie-tehnologii -upravleniya-sostoyaniem-cheloveka.-leonova-a.b.zpt-kuznecova-a.s

McCrae, Costa, 1989 - McCrae, R.R., Costa, P.T. (1989). Reinterpreting the Myers-Briggs Type Indicator from the Perspective of the Five-Factor Model of Personality. Journal of Personality. 57(1): 12-40.

Pavlova, 2017 - Pavlova, L.P. (2017). Dominanty deyatel'nogo mozga. Sistemnyi psikhofiziologicheskii podkhod $\mathrm{k}$ analizu EEG [Dominants of the active brain. Systemic psychophysiological approach to EEG analysis]. S-Petersburg: INFORM-NAVIGATOR, $442 \mathrm{p}$. [in Russian]

Pittenger, 1993 - Pittenger, D.J. (1993). Measuring the MBTI... and Coming Up Short. Journal of Career Planning \& Placement. January. [in Russian]

Psychological aspects..., 1976 - Psychological aspects and physiological correlates of work and fatigue. Ed. by E. Simonson and P. C Weiser. New York, 1976.

Sel'e - Sel'e G. Kontseptsiya stressa [The concept of stress]. [Electronic resource]. URL: https://econet.ru/articles/177393-gans-selie-kontseptsiya-stressa (date of access: 18.10.2020). [in Russian]

Shmelev, 2010 - Shmelev, A.G. (2010). Uzhe ne sotsionika, no eshche ne differentsial'naya psikhologiya [No longer socionics, but not yet differential psychology]. Vestnik YuUrGU. Seriya: Psikhologiya. 27(203): 104-108. [in Russian]

Sipps et al., 1985 - Sipps, G.J., Alexander, R.A., Friedt, L. (1985). Item Analysis of the Myers-Briggs Type Indicator. Educational and Psychological Measurement. 45(4): 789-796.

Sobchik, 2002 - Sobchik, L.N. (2002). Diagnostika individual'no-tipologicheskikh svoistv i mezhlichnostnykh otnoshenii [Diagnostics of individual-typological properties and interpersonal relationships]. S-Petersburg: Izd-vo «Rech'», 96 p. [in Russian]

Sokolova, 2005 - Sokolova, L.V. (2005). Razvitie ucheniya o biosotsial'noi prirode cheloveka $\mathrm{v}$ trudakh A.A. Ukhtomskogo [The development of the doctrine of the biosocial nature of man in the works of A.A. Ukhtomsky]. Diss. ... d-ra biol. nauk, spets. 03.00.13. S-Petersburg, 252 p. [in Russian]

Ukhtomskii, 2020 - Ukhtomskii, A.A. (2020). Dominanta [Dominant]. S-Petersburg: Izd-vo «Piter», 310 p. [in Russian]

Yung, 2017 - Yung, K.G. (2017). Ocherki po analiticheskoi psikhologii [Essays on Analytical Psychology]. Perevod S. Lorie, V.A. Polikarpov. Minsk: Izd-vo «Kharvest». [in Russian] 


\section{Управление функциональным состоянием изобретателя}

Александр Иванович Карманчиков а, *

а Удмуртский государственный университет, Ижевск, Российская Федерация

Аннотация. Объектом исследования в статье является система создания и защиты интеллектуальной промышленной собственности. Обращается внимание на возможности ускорения процесса поиска оптимальных эффективных решений, раскрываются возможности активизации творческой активности личности и творческих групп, выделяются возможности повышения эффективности творческой деятельности за счет учета психологических особенностей личности, специфики взаимоотношений разных типов личности в творческой группе.

Системный анализ создания объектов промышленной интеллектуальной собственности выявляет низкий уровень психологической культуры сотрудников предприятий. Специалисты и творческие группы, способные быстро выявлять технические проблемы и находить эффективные их решения, становятся всё более востребованной категорией на рынке труда. Всё более актуальной задачей становится создание творческих групп, эффективно использующих методы технического творчества для ускорения процесса поиска эффективных технических решений производственных проблем. Объективные результаты системного анализа методологии изобретательства позволяют более эффективно использовать интеллектуальные ресурсы вуза, региона и страны.

Мотивация к творческой деятельности, активизация поиска эффективных решений находятся в зависимости от эмоционального состояния изобретателя или творческой группы, эмоции становятся верными проводниками и отражением социальной информации в мир сознания, где эта информация осмысливается и перерабатывается.

Комплексный подход к системе поиска эффективных решений производственных проблем включает, как одну из важнейших, систему повышения эффективности «человеческих ресурсов».

Ключевые слова: системный анализ, методология изобретательства, активизация технического творчеств, психологические особенности личности.

\footnotetext{
${ }^{*}$ Корреспондирующий автор

Адреса электронной почты: karmai@bk.ru (А.И. Карманчиков)
} 